\title{
PROTECCIÓN Y ORDENACIÓN DEL MEDIO NATURAL EN CANTABRIA. NORMATIVA, INSTRUMENTOS Y CONFLICTOS TERRITORIALES
}

\author{
Carmen Delgado Viñas \\ Departamento de Geografía, Urbanismo y Ordenación del Territorio. Universidad de Cantabria \\ carmen.delgado@unican.es
}

\section{RESUMEN}

Los espacios naturales se han convertido en un factor esencial para la dinamización de los territorios en que se localizan como resultado de la creciente demanda social de valores ambientales. No obstante, el uso de los recursos de estas áreas, principalmente urbano y turístico, no está exento de riesgos por lo que es cada vez más imperiosa su protección y la planificación de su gestión.

En este artículo se hace un análisis de la normativa y los instrumentos de protección, ordenación y gestión de los espacios naturales en Cantabria así como de los peligros y amenazas que les están afectando, en particular los derivados de los procesos de urbanización difusa, que han adquirido una gran intensidad en las dos últimas décadas, sobre todo en las áreas litorales.

Palabras clave: Espacios Naturales Protegidos, Plan de Ordenación de los Recursos Naturales, Urbanización Extensiva, Ordenación del Territorio, Cantabria.

\section{ABSTRACT}

As a result of the increasing social demand for environmental values, Natural Areas have become an essential factor for revitalitation of the territories which they are located. However the use of land resources in these areas, mainly urban and tourist, it is not without

Fecha de recepción: febrero 2011.

Fecha de aceptación: julio 2012. 
risks reason why the protection and planning management of these spaces is increasingly imperative.

This article is an analysis of the norms and the instruments of protection, planning and management of the natural areas in Cantabria as well of the dangers and threats that are affecting to them, particularly those derive from the processes of urban sprawl, which have become very intense in the two last decades especially in coastal areas.

Key words: Protected Natural Areas, Natural Resources Management Plan, Urban Sprawl, Land Management, Cantabria.

\section{INTRODUCCIÓN}

La noción de espacio protegido que he utilizado aquí tiene un significado amplio, similar al que aplica la Unión Internacional para la Conservación de la Naturaleza (UICN) para definir las áreas protegidas (Dudley, 2008:10) que, por otra parte, coincide en gran medida con el del Convenio sobre la Diversidad Biológica (CBD). Ambas definiciones ponen de manifiesto, en mi opinión, la progresiva e imprescindible superación del tajante distanciamiento que ha existido muchas veces entre el enfoque, estrictamente conservacionista y naturalista, de la protección ambiental y la perspectiva de la ordenación y el planeamiento como instrumentos políticos y técnicos de control y gestión de los usos del territorio. Puede afirmarse que, a medida que se va imponiendo una visión integral del territorio, al menos en teoría, la protección tiende a introducirse como una categoría de la ordenación territorial al tiempo que se empieza a abordar el planeamiento urbanístico sostenible desde una perspectiva ambiental (Ministerio de Vivienda, 2010) ${ }^{1}$.

En correspondencia con el planteamiento anterior, he tomado en consideración en este estudio tanto los espacios naturales protegidos declarados a través de diferentes fórmulas (Red Cántabra de Espacios Naturales Protegidos -ENP-, Red Natura 2000, Humedales de Importancia Internacional -Convenio Ramsar-, etc.) como el conjunto de la franja litoral, afectada por la Ley de Costas y el Plan de Ordenación del Litoral (POL) elaborado por la Comunidad Autónoma de Cantabria.

El substancial aumento de la extensión superficial y del número de los espacios naturales protegidos en Cantabria, así como el de los nuevos instrumentos implementados en pro de su ordenación y gestión, han coincidido en el tiempo con la fase de apogeo de un espectacular proceso de expansión urbana y edificatoria. Tal simultaneidad no es un hecho trivial, sino un factor condicionante de gran trascendencia.

Sin embargo, es preciso destacar que la presión urbanística no ha sido igual sobre todas las áreas protegidas cántabras, sino que está relacionada con las características socioeconómicas y funcionales del contexto territorial en que se localizan. Los niveles de presión

1 Recientemente el Director General de Desarrollo Sostenible del Medio Rural ha abogado por incluir la gestión de los espacios naturales en el contexto de una política territorial con una visión «integral» del espacio rural, que tenga en cuenta «la totalidad de los aspectos» que incluyen tanto los componentes ambientales como los sociales, porque «no se puede entender la gestión de un espacio protegido habitado sin prestar atención y sensibilidad a la gente que está dentro». Ministerio de Medio Ambiente, Medio Rural y Marino (MARM), 15/11/2011. 
directa más bajos se dan todavía en las áreas protegidas interiores y de montaña, aunque ya han empezado a verse afectadas, mientras que las tensiones más intensas guardan estrecha relación con su localización en la proximidad de espacios muy urbanizados y litorales. De ahí que las mayores amenazas recaigan sobre los ENP situados en el litoral por lo que es en torno a ellos, también, donde están teniendo lugar los principales conflictos territoriales ${ }^{2}$.

\section{LOS ESPACIOS NATURALES DE CANTABRIA: PROTECCIÓN DEL MEDIO Y ORDENACIÓN DE LOS RECURSOS}

\section{Fundamentos legales y marco normativo e institucional}

El Estatuto de Autonomía de Cantabria establece en su artículo 23 que corresponde al Gobierno de la Comunidad Autónoma el desarrollo legislativo de los espacios naturales en el marco de la legislación básica del Estado, en ese momento la Ley 15/1975 de Espacios Naturales Protegidos, y, más tarde, la Ley 4/89 de Conservación de los Espacios Naturales y de la Flora y Fauna Silvestres ${ }^{3}$. A tenor de este mandato quedó instituida en 1986 la Comisión Regional de Medio Ambiente de Cantabria con unas competencias muy difusas y limitadas a conocer e informar proyectos «que se refieran a especies naturales protegidas o a la protección de la gea, flora, fauna y paisajes naturales» ${ }^{4}$.

Transcurrieron casi veinte años desde aquella fecha hasta la de elaboración y promulgación de la primera ley de ámbito autonómico en esta materia, la Ley de Cantabria 4/2006, de 19 de mayo, de Conservación de la Naturaleza de Cantabria ${ }^{5}$. Esta Ley continúa vigente en la actualidad sin haber experimentado modificación alguna tras la promulgación de la Ley 42/2007, de 13 de diciembre, del Patrimonio Natural y de la Biodiversidad.

La Ley cántabra clasifica los Espacios Naturales Protegidos en las siguientes categorías jurídicas en función de los bienes y valores que deben ser protegidos y de los objetivos de su declaración: Parques Nacionales, Parques Naturales, Reservas Naturales, Monumentos

2 Como han denunciado en diciembre de 2011 todas las organizaciones ecologistas de Cantabria, que lamentan la falta de desarrollo de los instrumentos de planificación y la escasez de recursos destinados a los ENP lo que, a su juicio, redunda en el hecho de que los vecinos de sus áreas de influencia vean los espacios protegidos como un «obstáculo» y se generen «hostilidades» hacia la conservación. Consideran, además, que los ENP litorales son los que están más degradados y amenazados por los planes de desarrollo de los municipios de su entorno. ABC y El Economista, 26 de diciembre de 2011, y El Diario Montañés, 27 de diciembre de 2011.

3 El traspaso a la Comunidad Autónoma de Cantabria de determinadas funciones y servicios en materia de conservación de la naturaleza, entre ellas la declaración de Parques Naturales, se hizo por Real Decreto 1.350/1984, de 8 de febrero.

4 Decreto 109/1986, de 30 de diciembre. Boletín Oficial de Cantabria (BOC) nº 6, de febrero de 1987. Unos años más tarde, en 1991 (Decreto 44/1991, de 12 de abril), se creó también el Consejo Asesor de Protección de la Naturaleza de Cantabria.

5 La Ley responde a lo dispuesto en el artículo 15.2 $2^{\circ}$ del Estatuto de Autonomía para Cantabria y se inscribe en el marco normativo de Derecho estatal y comunitario constituido por la Ley 4/1989, de 27 de marzo, de Conservación de los Espacios Naturales Protegidos y de la Fauna y Flora Silvestres y la Directiva 92/43/CEE del Consejo, de 21 de mayo de 1992, relativa a la conservación de los hábitat naturales y de la flora y fauna silvestres, transpuesta al Derecho interno por el Real Decreto 1997/1995, de 7 de diciembre. BOC n ${ }^{\circ} 105$, de 1 de junio de 2006. La Comisión Regional de Conservación de la Naturaleza es el órgano consultivo en las materias a que se refiere la Ley 4/2006; su composición y funciones quedaron reguladas por el Decreto 61/2007, de 24 de mayo. 
Naturales, Paisajes Protegidos, Zonas de la Red Ecológica Europea Natura 2000 y Áreas Naturales de Especial Interés.

De acuerdo con la normativa en vigor, la declaración de los Parques Naturales y de las Reservas Naturales corresponde al Parlamento de Cantabria mediante Ley; los Monumentos Naturales, los Paisajes Protegidos y las Áreas Naturales de Especial Interés se declararán por el Gobierno de Cantabria a través de Decreto; y las Zonas de la Red Ecológica Europea Natura 2000 serán declaradas por la Comunidad Autónoma por medio de Decreto del Gobierno de Cantabria.

Hasta el año 2003 la gestión de los Parques Naturales estuvo repartida entre dos Consejerías, la de Medio Ambiente y la de Ganadería, Agricultura y Pesca, generalmente con criterios y políticas diferentes. Desde esa fecha dichas competencias han recaído en exclusiva en la Consejería de Desarrollo Rural, Ganadería, Pesca y Biodiversidad (Consejería de Ganadería, Pesca y Desarrollo Rural en la actualidad).

La gestión de los Parques Nacionales, Parques Naturales, Reservas Naturales, Monumentos Naturales, Paisajes Protegidos, Zonas de Especial Protección de las Aves y Zonas Especiales de Conservación de las Especies Amenazadas Catalogadas corresponde a la dirección nombrada por el Consejero competente. Como órgano de participación social en la gestión de cada Parque Nacional y Parque Natural se instituyen los patronatos en los que están representados las administraciones públicas, los propietarios y demás titulares de intereses sociales y económicos relevantes, así como las asociaciones con fines de conservación análogos a los establecidos para el Parque ${ }^{6}$.

La Ley 4/2006 establece que la Consejería competente deberá elaborar y aprobar el Programa Director de Conservación de la Naturaleza, considerado como el instrumento básico de gestión que tiene que recoger las directrices, criterios, medidas y actuaciones precisas para la protección de los recursos naturales. Dicho Programa Director debería estar aprobado en un plazo inferior a dos años desde la entrada en vigor de la Ley, es decir, en 2008. Casi cuatro años después de haber finalizado el plazo, el Programa Director aún no ha visto la luz.

Del contenido de la Ley cabe resaltar la relativa novedad de la inclusión de los Paisajes Protegidos y las Áreas Naturales de Especial Interés así como la posibilidad de establecer formas de «Protección preventiva» y «Zonas Periféricas de Protección» de los espacios naturales destinadas a evitar impactos ecológicos o paisajísticos externos.

Por lo que se refiere al planeamiento de los recursos naturales, los instrumentos técnicojurídicos previstos para la gestión de los Espacios Naturales Protegidos en Cantabria son:

- Los Planes de Ordenación de los Recursos Naturales (PORN) y los Planes Rectores de Uso y Gestión (PRUG) en los Parques Nacionales, los Parques Naturales y las Reservas Naturales.

- Las Normas de Protección en los Monumentos Naturales, los Paisajes Protegidos y las Áreas Naturales de Especial Interés.

- En las Zonas de la Red Ecológica Europea Natura 2000 podrán aprobarse Planes de gestión específicos o cualquiera de los anteriores instrumentos de planeamiento «en el plazo de cuatro años desde la entrada en vigor de esta Ley».

6 Decreto 26/2007, de 8 de marzo, por el que se regulan la composición y funcionamiento de los Patronatos de los Parques Naturales de la Red de Espacios Naturales Protegidos de Cantabria. BOC n 60, de 26 de marzo de 2007. 


\section{Los instrumentos de protección, ordenación y gestión de la Red cántabra de Espacios Naturales Protegidos}

La Ley de Conservación de la Naturaleza de Cantabria ha entrañado, asimismo, la creación de la Red de Espacios Naturales Protegidos en la que se incluyen también las zonas de la Red Natura 2000 (Tabla 1). En la actualidad la Red cántabra de Espacios Naturales Protegidos tiene una extensión de 147.572 hectáreas, lo que representa el 27,73\% de la superficie regional $^{7}$, y está compuesta por treinta y siete espacios de los que veintinueve forman parte de la Red Natura 2000; los otros son: un Parque Nacional, seis Parques Naturales y un Monumento Natural (Figura 1).

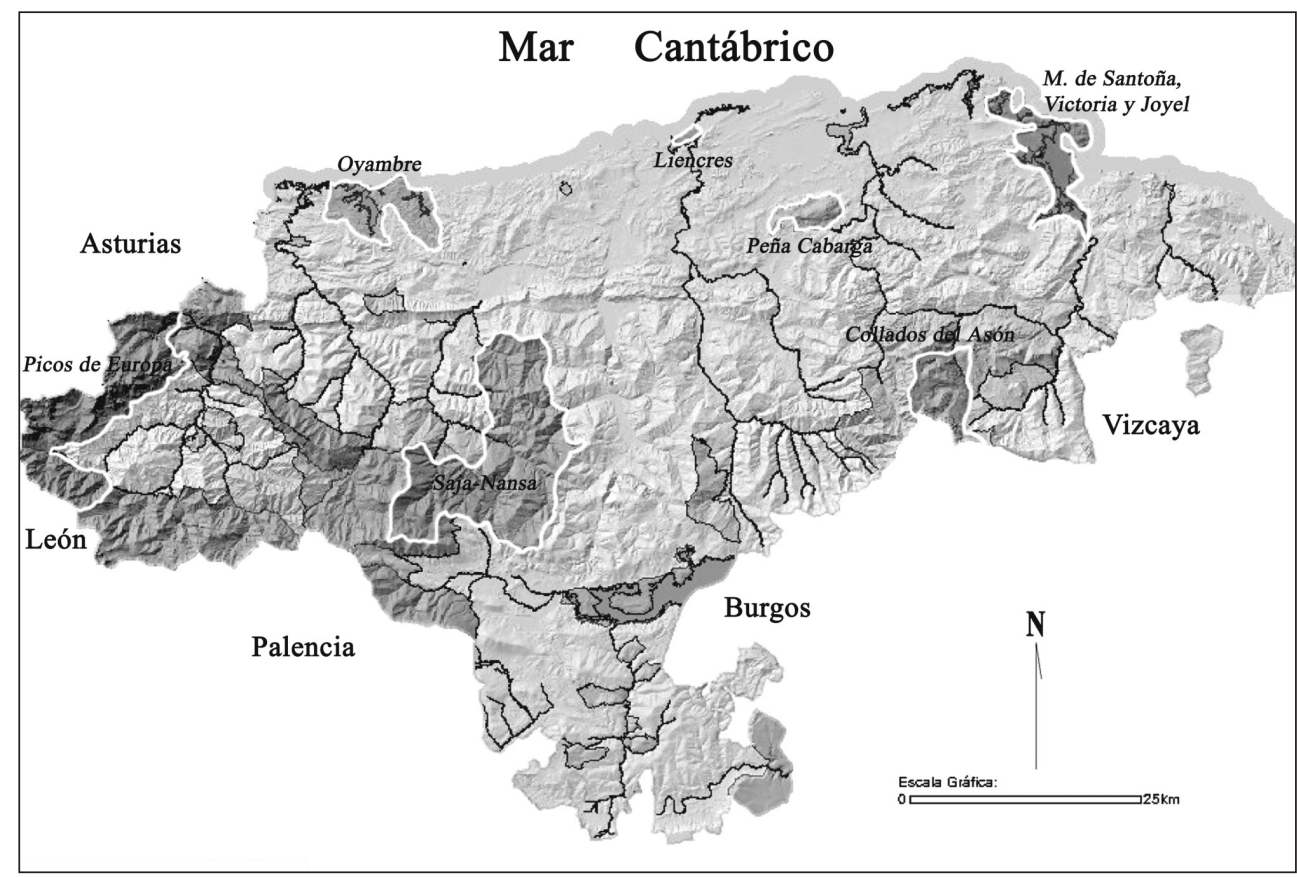

Fuente: elaboración propia a partir de cartografía del Gobierno de Cantabria, Consejería de Medio Ambiente, Ordenación del Territorio y Urbanismo, Dirección General de Ordenación del Territorio y Evaluación Ambiental Urbanística.

7 Anuario Estadístico. Cantabria 2011. Los datos proporcionados por Europarc difieren levemente: la superficie terrestre protegida es 154.884 hectáreas $(29,28 \%$ de la Comunidad Autónoma) a las que hay que añadir otras 1.055 hectáreas de superficie marina (EUROPARC, 2010:38). Sobre el origen y las características físicas y paisajísticas de los espacios naturales cántabros véase Frochoso, González y Lucio (2002).

8 La superficie total de las ZEPA cántabras es 79.110 ha y la de los LIC 137.555,98 ha. En total la superficie incluida en la Red Natura 2000 es 144.395 ha ya que la mayoría de ambos tipos de espacios se superponen. Por esa misma razón, la superficie total protegida no coincide con las sumas parciales puesto que muchos espacios están considerados en más de una figura de protección. 
Tabla 1

LARED CÁNTABRA DE ESPACIOS NATURALES PROTEGIDOS

\begin{tabular}{|c|c|c|c|}
\hline \multirow{2}{*}{ Figura de Protección } & \multicolumn{2}{|r|}{ Declaración } & \multirow{2}{*}{$\begin{array}{r}\text { Superficie } \\
\text { total (ha) }\end{array}$} \\
\hline & Año & Tipo de Norma & \\
\hline Parque Natural de las Dunas de Liencres & 1986 & Decreto $101 / 1986$ & 194,00 \\
\hline Parque Natural Saja-Besaya & 1988 & Decreto 25/1988 & $24.500,00$ \\
\hline Parque Natural de Oyambre & 1988 & Ley $4 / 1988$ & $5.758,00$ \\
\hline Parque Natural Macizo de Peña Cabarga & 1989 & Decreto 81/1989 & $2.588,00$ \\
\hline $\begin{array}{l}\text { Reserva/Parque Natural Marismas de Santoña, Victoria y } \\
\text { Joyel }\end{array}$ & $\begin{array}{l}1992 / \\
2006\end{array}$ & $\begin{array}{l}\text { Ley 6/1992 y Ley de Cantabria } \\
\text { 4/2006 }\end{array}$ & $6.978,33$ \\
\hline Parque Nacional Picos de Europa & 1995 & Ley $16 / 1995$ & $15.441,00$ \\
\hline Parque Natural Collados del Asón & 1999 & Ley $1 / 1999$ & $4.740,00$ \\
\hline Monumento Natural Sequoias del Monte Cabezón & 2003 & Decreto 41/2003 & 2,47 \\
\hline LIC Río Agüera & 2004 & Ley de Cantabria 4/2006 & 214,48 \\
\hline LIC Río Asón & 2004 & Idem & 530,49 \\
\hline LIC Río Camesa & 2004 & Idem & 245,66 \\
\hline LIC Río Deva & 2004 & Idem & 397,91 \\
\hline LIC Río y Embalse del Ebro & 2004 & Idem & $7.684,83$ \\
\hline LIC Río Miera & 2004 & Idem & 395,53 \\
\hline LIC Río Nansa & 2004 & Idem & 569,86 \\
\hline LIC Río Pas & 2004 & Idem & 957,29 \\
\hline LIC Río Saja & 2004 & Idem & 321,28 \\
\hline LIC Rías occidentales y Dunas de Oyambre & 2004 & Idem & $1.272,62$ \\
\hline LIC Costa central y Ría de Ajo & 2004 & Idem & 444,48 \\
\hline LIC Dunas del Puntal y Estuario del Miera & 2004 & Idem & 675,04 \\
\hline LIC Dunas de Liencres y Estuario del Pas & 2004 & Idem & 544,21 \\
\hline LIC Marismas de Santoña, Victoria y Joyel & 2004 & Idem & $3.701,47$ \\
\hline LIC Valles altos del Nansa y Saja y Alto Campoo & 2004 & Idem & $51.098,51$ \\
\hline LIC Liébana & 2004 & Idem & $42.546,08$ \\
\hline LIC Montana Oriental & 2004 & Idem & $21.679,00$ \\
\hline LIC Sierra del Escudo de Cabuérniga & 2004 & Idem & 787,02 \\
\hline LIC Sierra del Escudo & 2004 & Idem & $3.198,15$ \\
\hline LIC Cueva del Rejo en Val de San Vicente & 2004 & Idem & 180,00 \\
\hline LIC Cueva Rogería en Santillana del Mar y Alfoz de Lloredo & 2004 & Idem & 112,27 \\
\hline ZEPA Liébana & 2000 & Idem & $29.071,00$ \\
\hline ZEPA Sierra del Cordel y cabeceras del Nansa y Saja & 2000 & Idem & $16.244,00$ \\
\hline ZEPA Marismas de Santona, Victoria y Joyel y Ría de Ajo & 1994 & Idem & $6.904,00$ \\
\hline ZEPA Embalse del Ebro & 2000 & Idem & $6.711,00$ \\
\hline ZEPA Desfiladero de la Hermida & 2000 & Idem & $6.350,00$ \\
\hline ZEPA Sierra de Peña Sagra & 2000 & Idem & $5.020,00$ \\
\hline ZEPA Sierra de Hijar & 2000 & Idem & $4.730,00$ \\
\hline ZEPA Hoces del Ebro & 2000 & Idem & $4.080,00$ \\
\hline
\end{tabular}

Fuente: Gobierno de Cantabria. Consejería de Ganadería, Pesca y Desarrollo Rural. Anuario de Estadística Agraria 2011. 
El Parque Nacional de Picos de Europa se gestó a partir de la Ley de 22 de julio de 1918 por la que se creó el Parque Nacional de la Montaña de Covadonga o de Peña Santa en los Picos de Europa astur-leoneses. En 1995 tuvo lugar su nacimiento legal mediante la declaración como Parque Nacional de un área, ubicada sobre territorios de las Comunidades Autónomas del Principado de Asturias, Cantabria y Castilla y León, cuya conservación fue declarada de interés general de la Nación ${ }^{9}$. El Parque, integrado en la Red Estatal de Parques Nacionales, tiene una extensión total de 64.660 ha de las que 15.441 ha $(23,8 \%)$ corresponden a Cantabria y, concretamente, a los municipios lebaniegos de Tresviso, Camaleño y Cillórigo ${ }^{10}$.

De acuerdo con la Ley 4/1989 de Conservación de los Espacios Naturales, el PORN fue aprobado previamente ${ }^{11}$. En dicho documento todos los terrenos incluidos dentro del Parque Nacional, a excepción de los núcleos urbanos, quedaban clasificados como suelo no urbanizable objeto de protección especial. El planeamiento urbanístico de dichos núcleos, en consecuencia, tendría que atenerse a las directrices generales que, a tal efecto, contuviera el PRUG, que debería estar terminado en el plazo máximo de un año. El plazo fue ampliamente rebasado y el PRUG no fue aprobado hasta ocho años más tarde, en 2002 ${ }^{12}$, aunque en 2004, según denuncias de la Asociación para la Defensa de los Recursos Naturales de Cantabria (ARCA), seguía sin aplicarse ${ }^{13}$. La aprobación de la Ley de Parques Nacionales de 15 de marzo de 2007 otorgaba la gestión de los Parques Nacionales a las Comunidades Autónomas por lo que, en consecuencia, quedaron en suspenso y no vigentes los respectivos PORN y PRUG.

El de Picos de Europa es el último Parque Nacional que se ha transferido en España y el proceso de su traspaso ha sido el más complejo debido a que es el único cuya superficie se extiende por el territorio de tres Comunidades Autónomas diferentes. La transmisión de la gestión del Parque de Picos va a poner fin a seis años de provisionalidad relativa, en los que la gestión ha recaído en una comisión mixta formada por representantes del Ministerio de Medio Ambiente, el Gobierno de Cantabria, el Principado de Asturias y la Junta de Castilla y León; esta comisión mantendrá sus actividades hasta el 30 de septiembre de 2011 y a partir de entonces se disolverá. Desde el 1 de febrero de 2011 ha asumido la gestión del Parque Nacional de los Picos de Europa un Consorcio Interautonómico integrado por Cantabria, Principado de Asturias y Castilla y León, cuyas competencias se centran en la cooperación

9 Ley 16/95, de 30 de mayo, BOE no 129, de 31 de mayo de 1995.

10 En marzo de 2009 la Red de Parques Nacionales propuso la ampliación del Parque Nacional de Picos de Europa lo que implicaría la inclusión del término municipal Peñarrubia (Cantabria) y el concejo asturiano de Peñamellera Baja, que comparten el Desfiladero de la Hermida.

11 Real Decreto 640/94, de 8 de abril de 1994. BOE n 113 , de 12 de mayo de 1994.

12 Real Decreto 384/2002, de 26 de abril de 2002. BOE n ${ }^{\circ} 125$, de 25 de mayo de 2002.

13 El 9 de julio de 2003 la UNESCO aprobó la propuesta de reconversión del Parque en Reserva de la Biosfera. Desde esta perspectiva, no debe obviarse el hecho de que el Parque Nacional de Picos de Europa es, junto con los Parques Nacionales de Canarias, uno de los que más visitas anuales recibe: 1.774 .955 visitantes en 2007 y 1.712.668 en 2008 (EUROPARC, 2010:67), pese a lo cual, en 2009 aún no se había adherido a la Carta Europea de Turismo Sostenible. 
técnica, administrativa y económica entre las tres Comunidades y que será quien elabore, apruebe y ejecute los Planes Rectores de Uso y Gestión del Parque ${ }^{14}$.

El pequeño Parque Natural de las Dunas de Liencres y Abra del Pas fue declarado por el Decreto 101/1986, de 9 de diciembre, y unos meses más tarde se aprobó su Plan Rector de Uso y Gestión ${ }^{15}$ con el objetivo fundamental, entre otros, de aportar al patrimonio nacional e internacional una muestra representativa de la formación dunar ubicada en este área de la desembocadura del río Pas (Ría de Mogro). Transcurridos veinticuatro años desde la declaración, el Plan de Ordenación de los Recursos Naturales del Parque Natural de las Dunas de Liencres aún no ha sido aprobado, si bien, en noviembre de 2010, se envió el documento inicial para someterlo a evaluación ambiental.

El Parque Natural Saja-Besaya quedó establecido por el Decreto 25/1988, de 2 de mayo, para proteger una extensa zona forestal, constituida casi en su totalidad por montes de utilidad pública, que abarca parte de las cuencas de los ríos Saja y Besaya. Teniendo en cuenta que el ecosistema primigenio se encontraba sensiblemente alterado y que había disminuido mucho la superficie de arbolado por efecto de cortas e incendios, el objetivo principal era «arbitrar medidas complementarias de protección que afecten a las consecuencias de una excesiva humanización surgida del uso recreativo del monte y que no afecten a los usos tradicionales compatibles con el equilibrio del ecosistema, como son aquellos aprovechamientos forestales, de pastos y de caza».

El Plan Rector de Uso y Gestión fue aprobado en 1990 y modificado dos años después ${ }^{16}$. La aplicación de la normativa del PRUG tuvo algunas dificultades y resultó insuficiente y poco apropiada para la regulación de algunas actividades o para controlar las nuevas demandas sociales. Por esta causa se elaboró un segundo $\mathrm{PRUG}^{17}$, más actualizado, detallado y adecuado, que ha sido considerado modélico, en particular, en lo referido a la zonificación que establece las siguientes categorías:

- Zona de Reserva correspondiente a lugares excepcionales por su estado, fragilidad, singularidad o belleza, en los que se prohíbe todo aprovechamiento silvícola, cinegético y piscícola; el pastoreo podrá limitarse o prohibirse si no es compatible con los fines de conservación, lo mismo que el acceso de visitantes.

- Zona Forestal, que comprende la práctica totalidad de las áreas arboladas y las desarboladas cuyas características permitan y aconsejen la recuperación del bosque clímax

14 Real Decreto 1740/2010, de 23 de diciembre, de Ampliación de las funciones y servicios de la Administración del Estado traspasados a la Comunidad Autónoma de Cantabria, en materia de conservación de la naturaleza (Parque Nacional de los Picos de Europa). BOC n ${ }^{\circ}$ 35, de 29 de diciembre de 2010. La Comisión de Gestión del Consorcio Parque Nacional de Picos de Europa ha quedado constituida el día 3 de febrero de 2011. La presidencia de la Comisión tendrá carácter rotatorio y corresponderá a Castilla y León en 2011, Asturias en 2012 y a Cantabria en 2013. La dirección del Parque Nacional se ejercerá de forma colegiada por tres codirectores que representan a cada una de las Comunidades Autónomas implicadas; el codirector perteneciente a la Comunidad Autónoma que ejerza cada año la presidencia de la Comisión actuará como director-conservador.

15 Decreto 41/1987, de 10 de junio. La disposición adicional tercera de la Ley 4/2006, sin introducir ninguna modificación, realiza una descripción de los límites exteriores del Parque Natural de las Dunas de Liencres más precisa que la realizada en la norma declarativa.

16 Decreto 49/1990, de 9 de agosto. BOC n ${ }^{\circ} 176$, de 3 de septiembre de 1990 y Decreto 39/1992, BOC no 89, de 4 de mayo de 1992 .

17 Decreto 91/2000, de 4 de diciembre. BOC n ${ }^{\circ} 240$ de 15 de diciembre. 
por regeneración natural o repoblación artificial; se permiten los aprovechamientos silvícolas y el uso tradicional del pastoreo con restricción de las quemas controladas.

- Zona de Pastizal referida a las áreas que, por su localización, topografía, vegetación y uso tradicional, deben dedicarse al pastoreo, incluidas las áreas boscosas que sirvan de refugio natural al ganado; el pastoreo será regulado por los Planes Anuales de Aprovechamientos.

- Zona de Uso Recreativo compuesta por las áreas destinadas preferentemente al esparcimiento, acampada y picnic en las que se permiten las obras dirigidas a su adecuación recreativa.

- Zona Privada de Uso Agropecuario formada por el conjunto de fincas de propiedad privada (prados, invernales, edificaciones ganaderas y de vivienda) que forman parte del Parque Natural y cuya superficie asciende a 568 ha; en esta zona están permitidas las actividades agrícolas y ganaderas tradicionales.

- Zona del Conjunto Histórico-Artístico de Bárcena Mayor, que comprende el área urbana de esta localidad declarada Conjunto Histórico-Artístico.

- Zona de Influencia, en toda el área cercana al perímetro del Parque, en la que se fomenta la instalación de áreas recreativas con el fin de evitar una excesiva afluencia de visitantes en el interior del Parque.

Dentro del perímetro del Parque no se consiente la construcción de edificaciones, salvo las de uso público destinadas a la gestión del Parque y los refugios de montaña, de pastores o de ganado que se ajusten a la tipología constructiva y arquitectónica local.

En la actualidad se está trabajando en la preparación de un documento de bases ecológicas y en la definición de unidades ambientales para la zonificación del Parque Natural SajaBesaya como primera fase de la elaboración de un nuevo PRUG.

La declaración del Parque Natural de Oyambre se hizo a través de la Ley de Cantabria 4/1988, de 26 de octubre ${ }^{18}$ y acogiéndose a la Ley 15/1975, de Espacios Naturales Protegidos, que no exigía instrumentos específicos para la planificación en los espacios protegidos. El único instrumento previsto era un Plan Especial de Protección de la Zona Periférica Agrícola-Ganadera que debería redactarse en el plazo máximo de un año. No fue uno sino diez años pero, al fin, con fecha de 11 de mayo de 1998, la Comisión Regional de Urbanismo aprobó definitivamente el Plan Especial de Protección de la Zona Periférica Agrícola-Ganadera del Parque Natural de Oyambre. Más tarde, tras la tramitación legalmente prevista, se aprobó la revisión de las Normas Subsidiarias del Ayuntamiento de la villa de de San Vicente de la Barquera, incluida en los límites del parque.

El Plan Especial fue anulado por sentencia de 23 de junio de 2000 del Tribunal Superior de Justicia de Cantabria (TSJC). Posteriormente, a finales del año 2003, el Tribunal Supremo desestimó el recurso de casación interpuesto por el Gobierno de Cantabria y el Ayuntamiento de San Vicente de la Barquera contra la sentencia mencionada. El fallo del Tribunal Supremo confirmó la necesidad de redactar un Plan de Ordenación de los Recursos Naturales, tal y como establecía la Ley 4/1989, de Conservación de los Espacios Naturales y de la Flora y Fauna Silvestre, y, más tarde, la actual norma básica estatal, la Ley 42/2007, de Patrimonio Natural y de la Biodiversidad. La sentencia dio lugar a otras que anularon las Normas Sub-

$18{\text { BOC } \mathrm{n}^{\circ} 27}_{\text {, de }} 21$ de noviembre de 1988 y BOE n ${ }^{\circ} 302$, de 17 de diciembre de 1988. 
sidiarias de San Vicente de la Barquera, a consecuencia de lo cual se generó una situación de incertidumbre urbanística que ha pervivido hasta la actualidad.

La disposición adicional segunda de la Ley 4/2006 procedió a la modificación de la Ley por la que Oyambre había sido declarado Parque Natural en 1988, con objeto de permitir la adecuación de los instrumentos jurídicos de ordenación y gestión del Parque a los contemplados en la normativa en vigor. Así, se establece que los instrumentos básicos de ordenación del Parque Natural serán un Plan de Ordenación de los Recursos Naturales, que deberá aprobarse en el plazo máximo de seis meses desde la entrada en vigor de la Ley, y un Plan Rector de Uso y Gestión que tendrá que estar aprobado en un plazo máximo de dos años desde el momento en que aquél estuviera vigente.

Aunque el procedimiento de elaboración y aprobación del PORN del Parque Natural de Oyambre se había iniciado antes ${ }^{19}$, hasta principios de 2008 no empezó realmente a ponerse en marcha; desde entonces los anuncios de presentación inminente del borrador definitivo se han repetido frecuentemente $\mathrm{y}$, también reiteradamente, han sido incumplidos.

El proyecto de PORN fue sometido dos veces a información pública para asegurar la participación de todos los interesados y concertar el mayor consenso posible. En el borrador se establecían las categorías de zonificación siguientes, ordenadas de mayor a menor protección:

- La Zona de Uso Limitado en la que se incluyen los ríos y arroyos que componen la red hidrográfica, comprendiendo una franja de 25 metros en cada orilla de los cauces y otra de 100 metros de anchura colindante con la Unidad Ambiental «Rías y marismas».

- La Zona de Uso Compatible integrada por los terrenos incluidos en las Unidades Ambientales «Campiñas» y «Zonas forestales», que albergan valores de carácter ecológico, científico y paisajístico por situarse fuera de las áreas de influencia de los núcleos de población. En ella están completamente prohibidos los crecimientos urbanísticos, nuevas urbanizaciones, edificaciones y construcciones destinadas a uso residencial o turístico.

- La Zona de Uso General que comprende los terrenos de las Unidades Ambientales «Campiñas» $\mathrm{y}$ «Zonas Forestales» con menores valores ambientales por estar situados en las áreas de influencia de los núcleos de población ubicados íntegramente en esas Unidades, los suelos clasificados como urbanos o urbanizables con plan parcial aprobado definitivamente, la línea de ferrocarril Santander-Oviedo, la autovía del Cantábrico y las carreteras nacionales, autonómicas y municipales, todas ellas con sus zonas de dominio público, servidumbre y protección. En esta Zona están permitidos los desarrollos urbanísticos y la construcción de viviendas aisladas de carácter unifamiliar, si bien se primará la consolidación de los intersticios existentes frente a la ocupación de nuevos terrenos y no se localizarán urbanizaciones aisladas ni crecimientos en continuidad con núcleos existentes, apoyados en carreteras estatales o autonómicas, con el fin de impedir la formación de un continuo urbano.

A los efectos del PORN eran considerados Elementos de Régimen Singular el almacén de butano de San Vicente de la Barquera, el Polideportivo de las Tenerías, el Camping «El

19 Orden GAN 23/2005. BOC, n $^{\circ} 73$, de 18 de abril de 2005. 
Rosal», las explotaciones forestales de eucaliptos situadas en las marismas de Rubín y de Pombo y el Campo de Golf de las Dunas de Oyambre.

Los instrumentos de planificación y actuación previstos para la gestión y desarrollo del PORN son el Plan Rector de Uso y Gestión, el Plan de Desarrollo Sostenible y los Planes Técnicos Sectoriales. El plazo de elaboración de los dos primeros es de dos años y de tres años los últimos, contados siempre a partir de la entrada en vigor del PORN.

A finales de 2009 se realizó una nueva redacción del borrador para incorporar buena parte de las alegaciones presentadas. Los cambios introducidos eran tan importantes que se consideró necesario someter el documento a un nuevo período de información pública.

La modificación principal fue una redefinición de las zonas de ordenación que contempla como zonas de crecimiento las «áreas de influencia de los núcleos urbanos» y que, en consecuencia, se integran en las Zonas de Uso General, los únicos lugares del parque donde se permitirá a los Ayuntamientos desarrollar nuevas actuaciones y reclasificar suelo a urbanizable, así como aplicar una modificación de la Ley del Suelo que permite la construcción de vivienda unifamiliar aislada alrededor de núcleos. Este cambio en la zonificación ha conllevado una importante ampliación del suelo de uso general en detrimento del calificado como suelo compatible, mientras que el suelo de uso limitado se mantiene invariable.

Ante estos cambios la organización ecologista ARCA, tras presentar alegaciones, pidió que el proyecto de PORN se sometiera a un tercer proceso de información pública ya que, en su opinión, la nueva redacción del PORN «facilita esta brutal transformación del paisaje costero de Oyambre con el único propósito de que los constructores puedan sacar el máximo rendimiento edificatorio a los suelos urbanos y urbanizables» ${ }^{20}$.

No obstante, esa versión fue la definitiva y como tal es la que constituye el PORN que ha sido aprobado en diciembre de 2010, el primero de que dispone el Parque Natural veinticuatro años después de su declaración ${ }^{21}$.

Uno de los efectos indeseados del retraso en la aprobación del PORN ha sido el bloqueo de la redacción del PGOU de San Vicente de la Barquera, a la espera de la elaboración de aquél, y la paralización de la edificación de viviendas sociales y de un polígono industrial para cuya construcción el Ayuntamiento barquereño había adquirido cerca de $100.000 \mathrm{~m}^{2}$ de suelo.

A raíz de la catalogación del Macizo de Peña Cabarga como punto de interés geológico por parte del Instituto Geológico y Minero de España (1983) se iniciaron las primeras acciones para su proposición como espacio natural protegido. La declaración del Parque Natural del Macizo de Peña Cabarga se efectuó en 1989 por un Decreto de la Consejería de Ecología, Medio Ambiente y Ordenación del Territorio ${ }^{22}$ que fue anulado en mayo de 2005 por sentencia del Tribunal Superior de Justicia de Cantabria ya que nunca se puso en vigor el preceptivo Plan de Ordenación de los Recursos Naturales que, según señalaba el propio Decreto, debía ser elaborado y aprobado en el plazo de un año desde la declaración del Parque ${ }^{23}$. Asimismo,

20 El Diario Montañés, 03/06/2010.

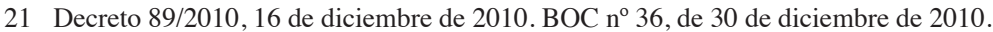

22 Decreto 81/1989, de 7 de noviembre. BOC n ${ }^{\circ} 38$, de 8 de noviembre de 1989.

23 La sentencia fue el resultado de un recurso interpuesto en 2003 por la compañía Duro Felguera S.A. que pretendía rellenar unos terrenos de su propiedad situados dentro del ámbito territorial del Parque Natural y cuya autorización denegó el Gobierno regional alegando esta condición. 
a diferencia de otros parques naturales cántabros, en este caso tampoco se había diseñado en los quince años transcurridos un PRUG. En la sentencia también se alude, como argumento, a la ausencia clara de los exigibles y preceptivos trámites de audiencia a los interesados, así como de la información pública y la consulta a las instituciones y los intereses sociales afectados.

Sin embargo, dado que la sentencia no se ha hecho firme, el Macizo de Peña Cabarga ha conservado su condición de Espacio Natural Protegido. Por otra parte, la Ley de Cantabria 4/2006 no preveía nada especial acerca de este espacio, por lo que ha mantenido su actual categoría de Parque Natural, lo que obliga a la elaboración de los preceptivos PORN y PRUG en virtud del artículo 20.3 de dicha Ley.

En mayo de 2008 se anunció el comienzo de los trabajos para la redacción del PORN y el 24 de junio de 2009 la Consejería de Desarrollo Rural publicó en el Boletín Oficial de Cantabria la orden por la que abría el proceso de redacción y aprobación del PORN para un espacio considerado como «un referente paisajístico regional y, singularmente, de la bahía de Santander, ya que constituye el mirador por excelencia de la marina central de Cantabria». Pese a los buenos propósitos de la Consejería, que estimaba que el proceso duraría hasta 2010, el documento inicial no ha sido enviado hasta noviembre de ese año para que se someta a la evaluación ambiental ${ }^{24}$.

La Ley 6/1992, de 21 de marzo $^{25}$, declaró la Reserva Natural de las Marismas de Santoña, Victoria y Joyel ${ }^{26}$. Uno de los argumentos esgrimidos para la declaración era que «Las actuales expectativas inmobiliarias están forzando su desecación, eliminando progresivamente las Marismas.» Por ello, los terrenos afectados por este régimen jurídico quedaron clasificados, a todos los efectos, como suelo no urbanizable de especial protección, con excepción de los suelos calificados como urbanos a su entrada en vigor, o que tuvieran reconocido por el planeamiento urbanístico un aprovechamiento que, con la aplicación de dicho régimen, diera lugar a indemnización de acuerdo con la legislación vigente.

Atendiendo a la excepcionalidad del caso, se elaboró la Ley sin la previa aprobación de un Plan de Ordenación de Recursos Naturales, en virtud de lo dispuesto en el artículo 15.2 de la Ley 4/1989, si bien, de acuerdo con la propia norma, debería aprobarse el PORN en el plazo máximo de un año. Pero no fue así tampoco en esta ocasión ya que el PORN tardó ocho años en ver la luz y lo hizo a través del Decreto 34/1997, de 5 mayo ${ }^{27}$.

Resulta sumamente elocuente la referencia explícita en el texto de dicho PORN a la incidencia que sobre el espacio natural de las marismas tienen las deficiencias de ordenación territorial y planeamiento urbanístico del ámbito en que se localizan, lo que ha influido en la aparición de diferentes conflictos entre los intereses ambientales y las aspiraciones urbanísti-

24 En los Anuarios de Estadística Agraria de 2010 y 2011, publicados por la Consejería de Ganadería, Pesca y Desarrollo Rural en 2011 y 2012 respectivamente, ha desaparecido toda referencia a este Parque Natural.

25 BOE de 30 de marzo de 1992.

26 La Ley fue declarada posteriormente inconstitucional de acuerdo con la Sentencia del Tribunal Constitucional 105/1998, de 1 de octubre, aunque la misma sentencia establecía la permanencia de la figura protectora hasta que se establecieran otras medidas que asegurasen su conservación. En 1993 el Reino de España había sido condenado por el Tribunal de Justicia de las Comunidades Europeas por no asegurar suficientemente la conservación de las Marismas y, especialmente, por no cumplir en este caso con las exigencias de la Directiva Aves. Las Marismas de Santoña, Victoria y Joyel son el único humedal cántabro integrado en el convenio RAMSAR.

27 BOC n 9 $^{\circ}$, de 15 de mayo de 1997 
cas a consecuencia, principalmente, de la inadecuada clasificación de determinados terrenos, la localización de usos en zonas poco apropiadas y la existencia de contradicciones espaciales en el nivel de conservación de los recursos naturales del territorio ${ }^{28}$.

El PORN establece cuatro categorías de zonificación:

- Zona de Reserva constituida por las Unidades Ambientales Primarias bien conservadas, excepto las playas, junto con la mínima superficie de amortiguación necesaria para garantizar dicha protección. En su interior podrán declararse zonas de Reserva Integral, con carácter temporal o permanente, en las que sólo se permitirán actividades relacionadas con la conservación y la investigación.

- Zona de Uso Moderado formada por las Unidades Ambientales Secundarias bien conservadas, las Unidades Primarias más alteradas y los terrenos que se consideran necesarios para asegurar una gradación progresiva entre la Reserva y el resto de las zonas.

- Zona de Uso Intensivo integrada por las Unidades Ambientales Secundarias más degradadas y los terrenos que se consideran necesarios para permitir la consecución de los objetivos marcados. Aquí están permitidos los servicios relacionados con el uso público o turístico (zonas recreativas, campamentos de turismo, aparcamientos, instalaciones deportivas, campos de golf, etc.) y, excepcionalmente, las viviendas familiares aisladas, siempre y cuando los instrumentos de desarrollo urbanístico determinen previamente las condiciones necesarias que garanticen la integración paisajística de estas viviendas, su armonía con el entorno, el empleo de tipologías adecuadas, la imposibilidad de formar núcleos de población, la protección de los valores ambientales y la consecución de los objetivos del PORN.

- Zona de Uso Especial compuesta por todos los terrenos no incluidos de forma específica en las zonas anteriores entre los que se encuentran playas, instalaciones asociadas a la gestión o al uso público, núcleos de población consolidados, tanto urbanos como rurales, terrenos para la expansión futura de los núcleos anteriores, infraestructuras actuales en el ámbito del PORN (viales principales, tendidos eléctricos) y elementos fuera de ordenación.

El artículo 91 del PORN aconsejaba «declarar Espacio Natural Protegido a la totalidad de los terrenos incluidos en el ámbito del PORN». Siguiendo esta recomendación, la declaración de Parque Natural de las Marismas de Santoña, Victoria y Joyel se hizo a través de la disposición adicional primera de la Ley 4/2006. Este hecho exigía que en el plazo de un año desde la entrada en vigor de dicha Ley se iniciara el procedimiento de revisión del PORN y en el plazo de dos años a partir de la vigencia de éste se aprobara el Plan Rector de Uso y Gestión.

Tampoco ahora se han cumplido los plazos. En noviembre de 2009 el Patronato del Parque adoptó el acuerdo de iniciar la revisión del PORN y unos meses más tarde el Consejero

28 «lo más significativo del análisis urbanístico es el escaso desarrollo del planeamiento en los municipios del entorno, muchos de los cuales han carecido de cualquier tipo de figura reguladora hasta hace pocos años... Lo más destacable de la evolución de los usos del suelo, en las últimas décadas, ha sido el notable incremento de la edificación, en detrimento de la superficie ocupada por las marismas, dunas, praderías y zonas de arbolado o matorral... En general, todo el conjunto está amenazado por la falta de control sobre las actividades turísticas y recreativas y la presión edificatoria» (los subrayados son míos). 
de Desarrollo Rural, Ganadería, Pesca y Biodiversidad anunció que esperaba que pudiera aprobarse a finales de 2012 .

El objetivo del Gobierno es revisar la planificación de esa área para poder gestionar las figuras de protección de diversa índole, recogidas en legislación nacional y europea, que protegen las Marismas de Santoña (Lugar de Interés Comunitario y Zona de Especial Protección para las Aves, entre otras). Pero el proceso puede ser complicado ya que existen conflictos pendientes de resolución: el Tribunal Supremo ha confirmado la sentencia que elevó los niveles de protección establecidos por el PORN vigente en seis zonas de Laredo, Noja, Arnuero y Argoños, ratificando así la sentencia dictada en 2007 por el TSJC, que estimó parcialmente un recurso de ARCA. Así mismo, la sentencia concede la máxima protección a una zona, la del Regatón de Laredo, lo que impide realizar en ella cualquier edificación, aun cuando el Gobierno de Cantabria le había concedido una categoría en la que cabía la construcción de viviendas unifamiliares aisladas. En la misma línea, el proyecto que está diseñando el Gobierno cántabro excluye del Parque Natural 179 hectáreas de terreno hasta ahora protegido.

El penúltimo espacio protegido declarado en Cantabria ha sido el Parque Natural de los Collados del Asón mediante la Ley 1/1999, de 18 de febrero ${ }^{29}$. Al igual que el Parque Natural Saja-Besaya, casi toda la superficie está constituida por montes de utilidad pública pertenecientes a varios pueblos del Ayuntamiento de Soba con una extensión de 4.020 hectáreas de monte público, la mayor parte de las 4.740 hectáreas que tiene el Parque en total.

También en este caso la declaración de Parque Natural se hizo sin la previa aprobación del Plan de Ordenación de los Recursos Naturales, pero en esta ocasión el PORN «sólo» ha tardado cinco años en ser alumbrado ${ }^{30}$. Este instrumento, que ha sido considerado ejemplar de forma casi unánime, establece también cuatro categorías de zonificación:

- Zonas de Uso General.

- Zonas de Uso Compatible que comprende, entre otras, las zonas privadas de uso agropecuario, prados de siega, terrenos con uso agrícola y ganadero intensivo.

- Zonas de Uso Limitado que toleran un moderado uso público que no requiera instalaciones permanentes. Se incluyen, entre otras, las áreas sometidas a aprovechamientos forestales y las áreas de uso ganadero de carácter extensivo (pastizales).

- Zonas de Reserva formada por los enclaves de mayor calidad biológica o que contengan en su interior los elementos bióticos más frágiles, amenazados o representativos.

Además de las normas y directrices habituales relativas a la protección y conservación de recursos naturales, en el PORN se establecen otras relativas a la protección y conservación del paisaje ${ }^{31}$ y la prohibición de instalar o construir infraestructuras asociadas a aprovecha-

29 BOC n $^{\circ} 2$, de 19 de febrero de 1999.

30 Decreto 2/2004, de 15 de enero. BOC, $\mathrm{n}^{\circ} 17$, de 27 de enero de 2004.

31 «Se tendrán como objetivos el preservar el paisaje como un recurso más, manteniendo un equilibrio sostenido en sus aprovechamientos y usos, evitar y minimizar los impactos paisajísticos producidos por las actividades que se pretendan desarrollar y recuperar las características paisajísticas de las zonas degradadas por actividades desarrolladas con anterioridad ...Se evitará la introducción de elementos artificiales en el medio natural que limiten el campo visual, rompan la armonía del paisaje o desfiguren la perspectiva. Se promoverá la conservación del estilo arquitectónico tradicional y la estética de las edificaciones aisladas. Se procurará que los cercados se realicen según los métodos tradicionales». 
mientos hidráulicos y eólicos, salvo las que autorice la Administración del Parque por motivos de gestión o conservación.

Recientemente se ha anunciado la constitución formal de un grupo de trabajo para la elaboración del Plan Rector de Uso y Gestión si bien, el hecho de que la misma noticia se haya publicado dos veces con un año de diferencia, no permite albergar muchas expectativas sobre su funcionamiento real ${ }^{32}$.

Aparte de los Parques Naturales, no se ha adoptado ninguna figura de protección diferente con la salvedad del Monumento Natural de las Sequoias del Monte Cabezón, declarado en $2003^{33}$ para proteger una masa forestal de Sequoia sempervirens que fue plantada a finales de los años cuarenta y presenta una fisonomía espectacular, tanto por las dimensiones de los pies como por el carácter denso y cerrado de la masa. La singularidad de este bosquete, que le hace acreedor de especial protección, reside en que se trata de una especie inusitada en Cantabria y de la que apenas existen en España ejemplares en estado seminatural.

\section{LA SALVAGUARDA DEL LITORAL: LA LEY DE COSTAS Y EL PLAN DE ORDENACIÓN DEL LITORAL}

Como en todo el territorio español, la protección y ordenación de la franja litoral cántabra está regida por la Ley 22/1988, de 28 de julio, Ley de Costas, cuya finalidad es la determinación, protección y ordenación del uso del dominio público marítimo-terrestre y, en especial, de la ribera del mar.

La Ley de Costas tiene un marcado carácter ambientalista y proteccionista pero no es ajena a una concepción integrada de las directrices básicas de la ordenación del litoral, que puede considerarse precoz en España. La Ley define el dominio público marítimo-terrestre y establece una franja de servidumbre de seis metros seguida de otra de protección de cien metros desde el límite interior de la ribera del mar (20 metros en el caso de los terrenos clasificados previamente como suelo urbano), en los que se pueden instalar campos deportivos o cultivos pero queda prohibido cualquier tipo de construcción (disposición transitoria octava), además de definir una zona de influencia de 500 metros donde se controla la edificación. En teoría, la Ley daba un plazo de cinco años para completar el deslinde del dominio público marítimo-terrestre, pero el proceso prácticamente estuvo paralizado hasta 2004, año a partir del cual experimentó una gran aceleración.

Por su parte, la Comunidad Autónoma de Cantabria ha implementado normas y desarrollado iniciativas tendentes a la preservación, ordenación y gestión de sus propios espacios litorales.

El marco normativo fundamental de ordenación territorial en Cantabria es la Ley 2/2001, de 25 de junio, de Ordenación Territorial y Régimen Urbanístico del Suelo de Cantabria $\left(\right.$ LOTRUSCA) ${ }^{34}$. De las Disposiciones Adicionales de dicha Ley proceden las principales

32 El Diario Montañés, 19/11/2009 y 17/11/2010. En la segunda ocasión con el añadido optimista de que el documento inicial estará redactado en el verano de 2011.

33 Decreto 41/2003, de 30 de abril. BOC n 94, de 19 de mayo de 2003.

34 Sobre estos aspectos véase Delgado, 2010, donde trato sobre el planeamiento y la ordenación territorial en Cantabria con más amplitud y detalle. 
herramientas de ordenación y planeamiento vigentes en la actualidad, entre ellas el Plan de Ordenación del Litoral (POL).

El POL, que puede ser considerado como el primer instrumento de ordenación territorial propiamente dicho elaborado, promulgado y aplicado por la Comunidad Autónoma, alcanzó rango legal definitivamente a través de la Ley de Cantabria 2/2004, de 27 de septiembre, del Plan de Ordenación del Litoral ${ }^{35}$ cuyo objetivo principal es asegurar una protección efectiva e integral para el área costera de la Comunidad Autónoma.

El POL establece los criterios generales de protección del medio y el paisaje litoral y de ordenación de usos y actividades en ese ámbito, al tiempo que orienta las estrategias de crecimiento urbanístico y la implantación de infraestructuras.

En la Memoria de Ordenación del POL queda definido el modelo territorial a partir de tres zonas básicas:

- Área de Protección en la que se distingue, a su vez, entre la Protección Ambiental y la Protección Litoral con diferentes categorías de protección (Costera, Intermareal, de Riberas, Ecológica y de Interés Paisajístico).

- Área de Ordenación constituida por las zonas de territorio cuyas directrices de planificación exigen la intermediación municipal a través del instrumento de ordenación urbanística por excelencia, el Plan General de Ordenación Urbana. Dentro de ésta se distingue un Área Litoral y un Área No Litoral con diferentes categorías de ordenación según la capacidad de carga del territorio (área periurbana, área de modelo tradicional y área de ordenación ecológico-forestal).

- Las áreas de Actuaciones Integrales Estratégicas concebidas como ámbitos adecuados para el desarrollo singular de políticas sectoriales estratégicas de carácter territorial en materia de vivienda, medioambiente e industria. A su vez se clasifican en tres grandes grupos: Actuaciones Integrales Estratégicas de Reordenación, de Recuperación Ambiental e Industriales.

En cuanto a los desarrollos urbanísticos, la Ley recoge un concepto fundamental para la planificación, el de la «capacidad de acogida», que es el máximo crecimiento urbanístico que un territorio puede soportar atendiendo a las dinámicas de población, actividad económica, disponibilidad de recursos, infraestructuras y equipamientos.

El ámbito de aplicación del POL se definía también en la Disposición Adicional Cuarta de la Ley 2/2001 como el territorio de los 37 municipios litorales de la región ${ }^{36}$ exceptuados los suelos urbanos, los suelos urbanizables con Plan Parcial aprobado definitivamente y las áreas sometidas a algún régimen especial de protección por corresponder a algún Espacio Natural Protegido o por tener un Plan de Ordenación de los Recursos Naturales (PORN) en vigor (Figura 2).

35 BOC n $^{\circ} 21$, de 28 de septiembre de 2004.

36 El POL afecta a un área de $1.260 \mathrm{~km}^{2}$, que se extienden a lo largo de los $212 \mathrm{~km}$ de la costa cántabra y se adentran $6 \mathrm{~km}$ hacia el interior. 


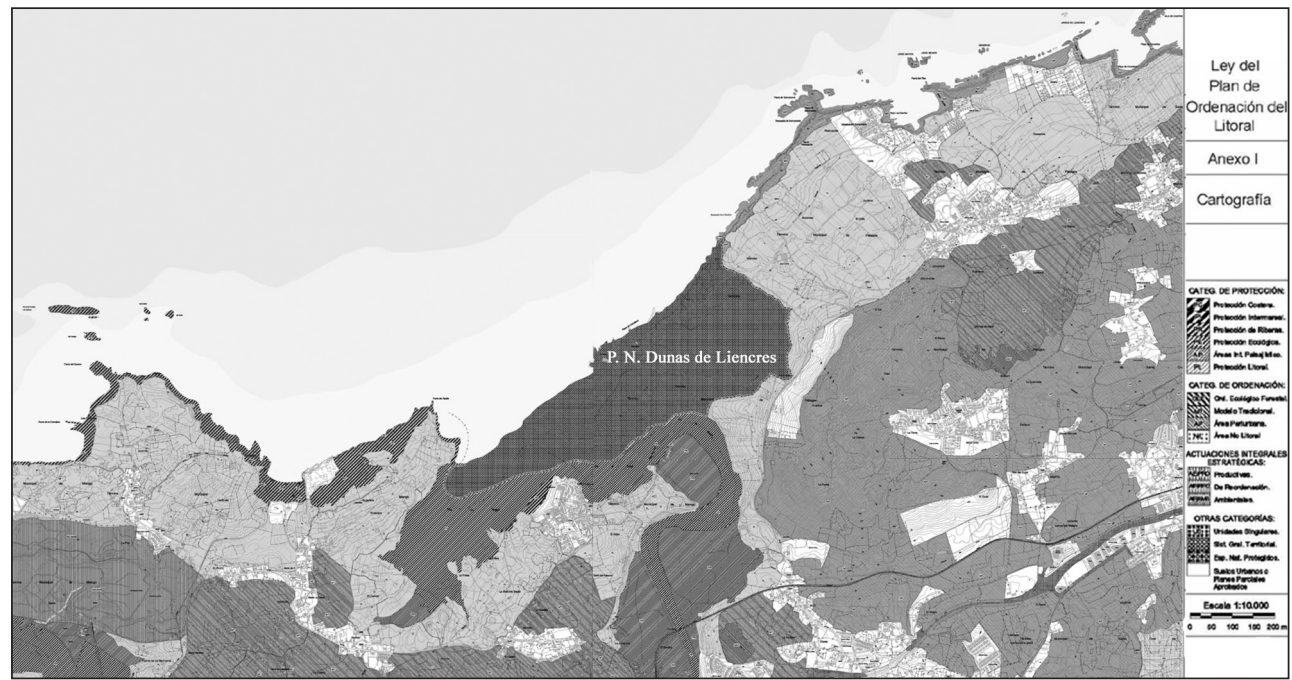

Fuente: reelaboración a partir de cartografía del Gobierno de Cantabria, Dirección General de Ordenación del Territorio, Ley del Plan de Ordenación del Litoral (POL).

No obstante, en el artículo 3 de la Ley 2/2004 se contemplan posibles modificaciones del ámbito del POL en un número limitado de casos. Así, en situaciones excepcionales y motivadas, el Consejo de Gobierno de Cantabria está habilitado para modificar mediante Decreto el ámbito del POL, con la exclusión o inclusión en él de los terrenos correspondientes a suelos en los que se acredite que, en el momento de adaptación del planeamiento municipal al POL, reúnen o no los requisitos legales para ser clasificados como urbanos ${ }^{37}$. En el mismo caso se encuentran los suelos en los que se anule mediante sentencia judicial firme un Plan Parcial, aquéllos en los que se produzca la ampliación o reducción del ámbito de un Plan de Ordenación de los Recursos Naturales (PORN) o del área de un Espacio Natural Protegido, siempre que sean situaciones sobrevenidas con posterioridad a la aprobación del $\mathrm{POL}^{38}$.

Los municipios afectados quedaban obligados por ley a iniciar la adaptación de su planeamiento urbanístico al Plan de Ordenación del Litoral en el plazo de un año contado desde su entrada en vigor. Los tiempos han sido ampliamente superados y, casi ocho años después de la aprobación del POL, sólo cuatro municipios (Argoños, Santillana del Mar, Comillas y

37 Así se han incorporado en febrero de 2011 al ámbito de aplicación del Plan de Ordenación del Litoral los terrenos de varias urbanizaciones del municipio de Piélagos con la finalidad de que recuperen la condición de suelo residencial que tuvieron en sus orígenes y que perdieron como consecuencias de sentencias judiciales en las que se dictó la orden de su demolición. Con ello no parece que se pretenda eludir el cumplimiento de las sentencias de derribo, entre otras razones porque la mayor parte de dos dichas urbanizaciones (Cerrias I y Cerrias II en Liencres) se encuentran afectadas por la Ley de Costas ya que están construidas sobre dominio público marítimo terrestre.

38 Es lo que explica la última modificación de los límites del POL (diciembre de 2011) con motivo de la aprobación del Plan de Ordenación de los Recursos Naturales (PORN) del Parque Natural de Oyambre un año antes. 
Medio Cudeyo) tienen aprobados planes adaptados a dicha Ley; otro más, Santander, está a punto de obtener la aprobación definitiva.

\section{CONSTRUCCIÓN RESIDENCIAL Y URBANIZACIÓN EXTENSIVA VERSUS PROTECCIÓN Y ORDENACIÓN: LOS CONFLICTOS TERRITORIALES EN LAS ÁREAS PROTEGIDAS LITORA- LES DE CANTABRIA}

En Cantabria ha tenido lugar un proceso progresivamente acelerado de urbanización del territorio y, en definitiva, de artificialización del suelo, al igual que ha ocurrido en la mayor parte del territorio español.

Si tomamos como referencia los datos aportados por el Observatorio de la Sostenibilidad en España (OSE) en su informe sobre los Cambios de ocupación del suelo en España (2006), en el período 1987-2000 las superficies artificiales han aumentado aquí en 22,1\%. La mayor parte de ese incremento ha correspondido a las zonas urbanas, que han experimentado un crecimiento en términos absolutos de 879,9 hectáreas (9,9\% de aumento) pasando a representar en el año 2000 el 70,7 \% de la superficie artificial. En los primeros cinco años del siglo XXI se han artificializado cerca de otras 2.000 hectáreas (OSE, 2010), más del doble que en los trece años del período anterior.

Buena parte del territorio artificializado corresponde a suelo consumido para la construcción residencial, una actividad que ha tenido en Cantabria un auge espectacular desde mediados de los años noventa del siglo XX, en particular en los municipios litorales. Si consideramos los datos proporcionados por el último Censo de Población y Vivienda, sólo en el decenio 1991-2001 se han edificado en Cantabria 58.683 viviendas, el 26,0 \% del parque inmobiliario regional a comienzos del siglo XXI. El ritmo constructivo se ha ido avivando gradualmente hasta culminar a mediados de la primera década de la actual centuria. De acuerdo con los datos proporcionados por el Colegio Oficial de Aparejadores y Arquitectos Técnicos de Cantabria, en los casi trece años comprendidos entre 1998 y 2010 se visaron contratos de obra para la construcción de 123.193 nuevas viviendas, que representan el 54,6 $\%$ del total de viviendas censadas en 1991 (Figura 3).

Como en otras regiones españolas, también en Cantabria la ordenación del territorio, la protección del medio natural y el planeamiento del uso de los recursos de los espacios protegidos se han retrasado demasiado para poder controlar o, al menos, gestionar adecuadamente el exagerado desarrollo de la construcción residencial (Delgado, 2008). Es esto lo que explica que, algunos años después de la entrada en vigor de los principales instrumentos de protección y ordenación, en el litoral de Cantabria existan situaciones conflictivas calificadas como «puntos negros» en la terminología de los informes anuales elaborados por Greenpeace bajo el título Destrucción a toda costa.

En no pocas ocasiones, los conflictos urbanísticos están relacionados con las agresiones directas que sufren los Espacios Naturales Protegidos carentes de planeamiento o con planeamiento insuficiente. Entre otras razones porque la elaboración y puesta en vigor de los instrumentos básicos de ordenación y gestión se está retrasando mucho y, en consecuencia, todavía son bastante limitados.

Tal es el caso, no excepcional, del Parque Natural de Oyambre en cuyo interior la empresa Golf Santa Marina promovió a finales de los años noventa la construcción de un complejo 


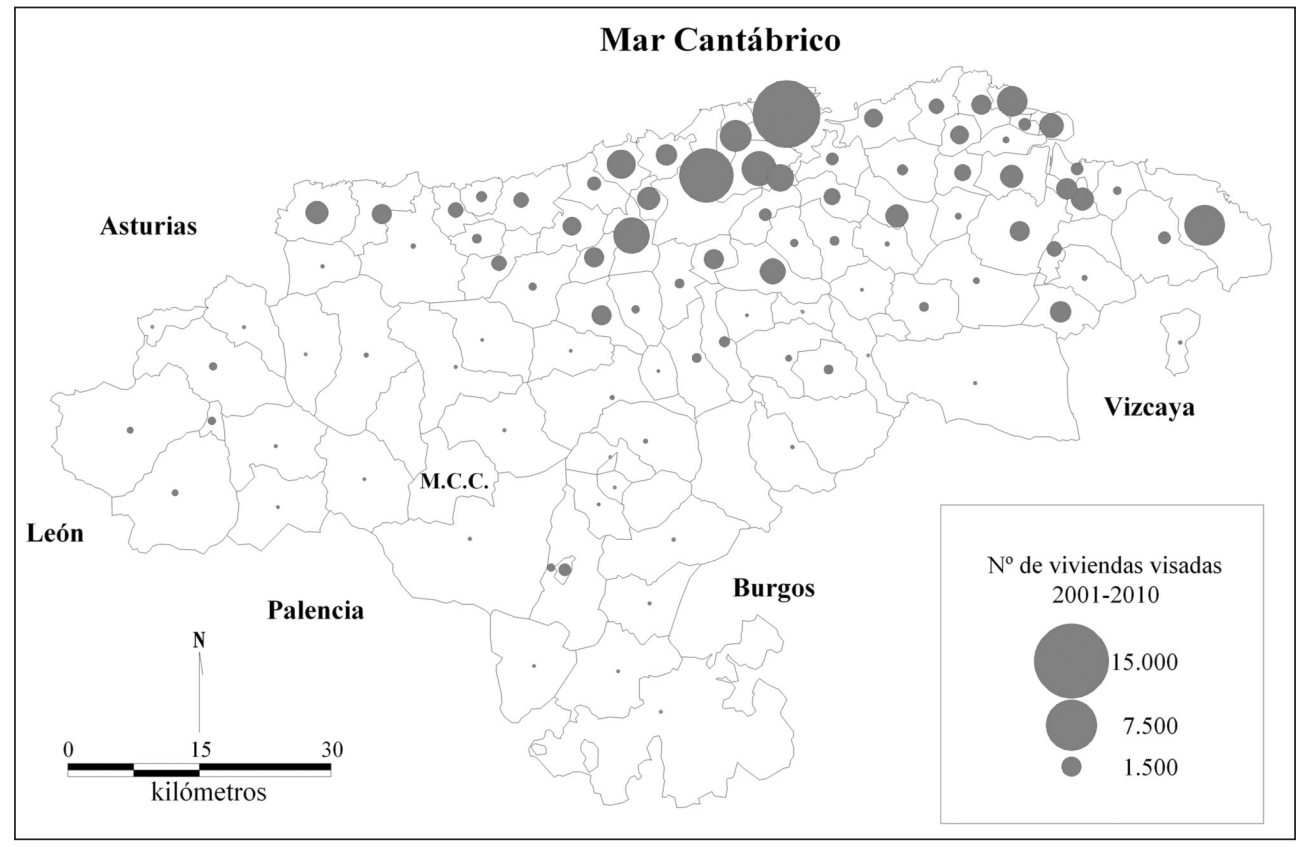

Fuente: elaboración propia con los datos aportados por el Colegio Oficial de Aparejadores y Arquitectos Técnicos de Cantabria.

turístico-residencial de 72 hectáreas que constaba de un campo de golf, 350 chalets y un hotel de lujo.

Como se ha dicho antes, en 1998 la Comisión Regional de Urbanismo de Cantabria (CRU) aprobó definitivamente el Plan Especial de Protección de la Zona Periférica AgrícolaGanadera; a partir de él se procedió a la Revisión de las Normas Subsidiarias del Ayuntamiento de San Vicente de la Barquera y a la redacción del Plan Parcial de la Urbanización Santa Marina (1999) al que, en diciembre de 2000, la Comisión Regional de Urbanismo (CRU) y el Gobierno de Cantabria dieron luz verde.

En noviembre de 2002 el TSJC declaró ilegal el Plan Parcial, después de haber anulado sucesivamente el Plan Especial de Oyambre y las Normas Subsidiarias del Ayuntamiento de San Vicente de la Barquera. El proceso se prolongó durante los años siguientes hasta que, en junio de 2006, el Tribunal Supremo confirmó los sucesivos fallos emitidos por el tribunal cántabro. La urbanización no terminó de construirse, pero sí algunas infraestructuras, los viales y un campo de golf (Figura 4).

Recientemente, el proyecto de Plan General de Ordenación Urbana de San Vicente de la Barquera ha vuelto a poner sobre la mesa el Plan Parcial Santa Marina al tiempo que uno de los socios, la empresa Inmobiliaria Montañesa, ha solicitado la ejecución firme de las sentencias como paso previo para presentar una reclamación por «responsabilidad patrimonial» 


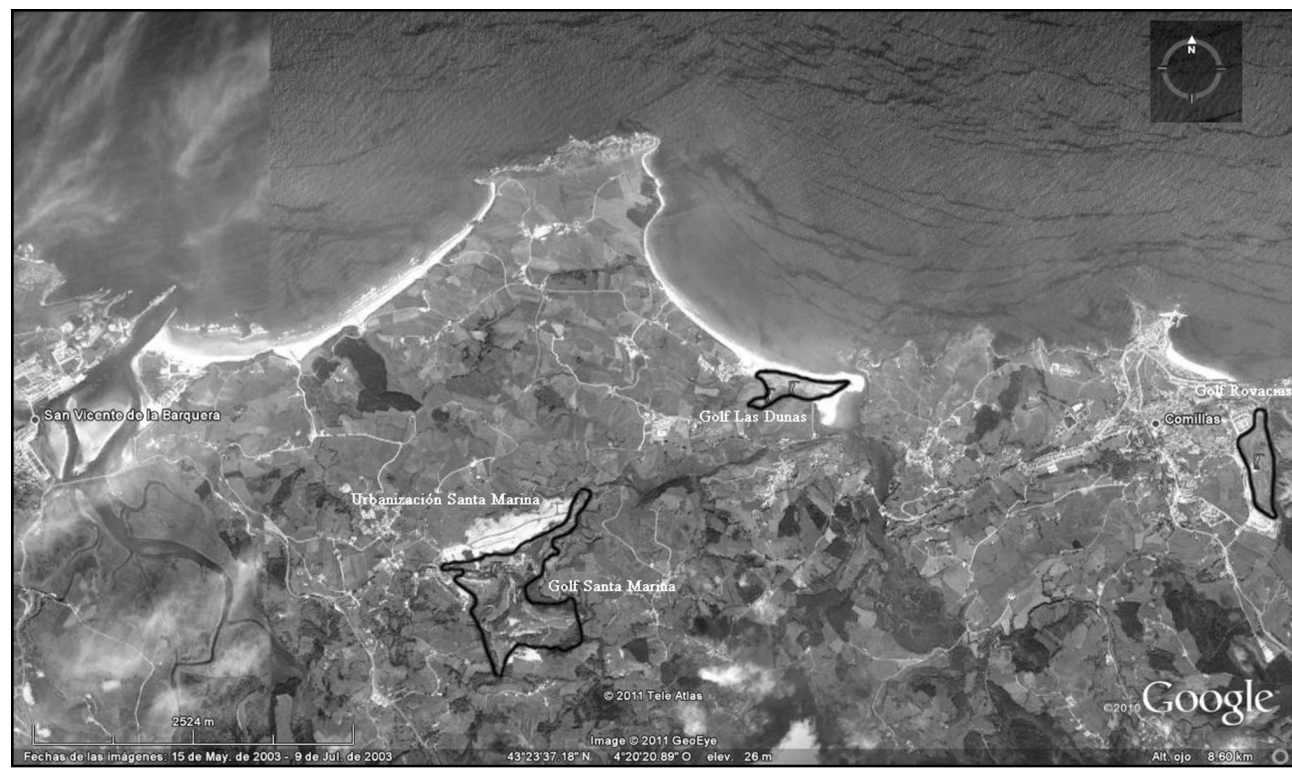

Fuente: reelaboración a partir de imágenes de Google Earth.

y pedir al Gobierno de Cantabria una compensación por el daño sufrido, que cifran en no menos de cien millones de euros. Una acción no compartida por los otros propietarios y promotores del Plan Parcial, partidarios de llegar a un punto de encuentro con la Administración, introduciendo las modificaciones necesarias sobre el proyecto inicial para que, ajustándose a la normativa, se pueda ejecutar el proyecto en la dimensión que se considere adecuada en el nuevo marco legal que se estaba redactando, en referencia al PORN del Parque de Oyambre.

Las expectativas de seguir adelante con el proyecto han aumentado con la aplicación de la penúltima modificación de la Ley del Suelo cántabra, que se ha aprobado en 2009 para permitir el cambio de uso y rehabilitación de inmuebles en el medio rural. El mismo efecto parece haber tenido la definitiva versión del PORN en la que la figura de Elementos de Régimen Singular, que deben desaparecer, tan sólo afecta a los que se encuentran en la Zona de Uso Limitado y no a los que estén en Zona de Uso Compatible, donde se halla Santa Marina. No obstante, otra providencia dictada, también en 2009, por el TSJC obligaba al Ayuntamiento de San Vicente de la Barquera a proceder en el plazo máximo de seis meses a cumplir la sentencia de la anulación del Plan Parcial de Santa Marina ${ }^{39}$.

39 En mayo de 2011 el TSJC se ha pronunciado en el sentido de instar al derribo inmediato de las obras previas de urbanización efectuadas cuando los promotores contaban con todos los permisos para ejecutar el complejo urbanístico. La demolición de Santa Marina ha sido incluida en el plan de derribos presentado al TSJC por el Gobierno de Cantabria. El PGOU de San Vicente de la Barquera ha sido aprobado inicialmente por la Corporación Municipal en agosto de 2011. En el proyecto del Plan se prevé la construcción de 1.600 viviendas, preferentemente de primera residencia, para atender a las necesidades de la población residente. En él se contempla también la revitalización del proyecto de Santa Marina, si bien haciendo cambios en la ubicación de las viviendas y la zona hotelera para que no afecta al área que está dentro de los límites del Parque Natural de Oyambre. 
En las proximidades de Santa Marina se encuentra otro campo de golf, el de las Dunas de Oyambre, ubicado sobre el propio sistema dunar y en la zona de servidumbre de protección del dominio público marítimo terrestre, incumpliendo la Ley de Costas (Figura 4) ${ }^{40}$. En el proyecto de PORN se declaraba el campo de golf, situado dentro del área de especial protección, como Elemento de Régimen Singular, lo que fijaba su incompatibilidad y conllevaba la necesidad de abordar su regeneración ambiental en el plazo de cinco años desde la entrada en vigor del PORN. En el documento aprobado finalmente es considerado como un «elemento fuera de ordenación» y, en consecuencia «en tanto que la Administración Gestora no adopte las actuaciones pertinentes para promover su adecuación o eliminación, podrá seguir funcionando sin más limitaciones que las especificadas en los diferentes apartados del PORN $»^{41}$.

El conflicto se ha agudizado con las obras de mejora y construcción de una variante de la carretera que atraviesa el corazón del Parque Natural de Oyambre, casi en paralelo a las playas de Merón y Oyambre, entre el Puente Zapedo (Valdáliga) y el Puente de la Maza (San Vicente de la Barquera). Las obras han sido denunciadas por la organización Ecologistas en Acción al considerarlas un atentado al medio ambiente, especialmente por el trazado elegido, junto a la playa de Oyambre y junto al campo de golf, que, si bien evita el paso por la zona dunar, tiene un gran impacto ya que contribuye a la degradación de la marisma al romper su conectividad con la playa. Contra la construcción de la variante se ha movilizado un colectivo formado por once asociaciones ecologistas y conservacionistas que denuncian que la obra favorece los intereses privados del campo de golf que se localiza en sus proximidades.

Las obras del polémico tramo fueron paralizadas de forma cautelar por orden judicial de acuerdo con un auto de fecha 5 de noviembre de 2010 de la Sala de lo Contencioso Administrativo del TSJC, que acepta en parte la petición hecha por Ecologistas en Acción por entender que la construcción del nuevo vial puede causar un grave daño ambiental. Pese a lo cual, la carretera ha sido inaugurada por las autoridades regionales en febrero de 2011 a falta de la terminación de los tramos paralizados por orden judicial.

Una de las causas fundamentales de la conflictividad generada en torno al Parque Natural de Oyambre reside en el hecho de que los espacios urbanos han seguido formando parte del Parque, incluida la propia villa de San Vicente, que tiene unos 3.500 habitantes permanentes y un importante volumen de población vinculada estacional durante el verano.

Una situación parcialmente diferente a la del Parque Natural de las Marismas de Santoña, Victoria y Joyel sobre el que también se ciernen las amenazas urbanísticas (Figura 5).

Argoños es uno de los términos municipales que se ha visto más perjudicado por un modelo de desarrollo urbanístico insostenible y nada respetuoso con la legalidad y el entorno natural en que se encuentra. El mero anuncio de inicio de la revisión del PORN ha generado expectativas de «legalización» de un buen número de las casi trescientas viviendas sobre las que pesan sentencias firmes de derribo. Es evidente que el trámite para hacerlo sería largo, puesto que incluye la revisión, a su vez, del Plan General de Ordenación Urbana del munici-

40 El campo de golf de Las Dunas de Oyambre, el más antiguo de España, fue fundado en 1924 por el conde de Güell, marqués de Comillas.

41 Gracias a una de las disposiciones transitorias su pervivencia se mantiene siempre que subsista una concesión administrativa previa, un hecho que confirmó la Audiencia Nacional mediante una sentencia concluyente que reconoció el derecho de explotación de las instalaciones deportivas a la firma concesionaria Silver Eagle por un mínimo de treinta años y un máximo de sesenta. 
Figura 5

NÚCLEOS Y ÁREAS URBANAS EN LAS INMEDIACIONES DEL PARQUE NATURAL DE LAS MARISMAS DE SANTOÑA, VICTORIA Y JOYEL

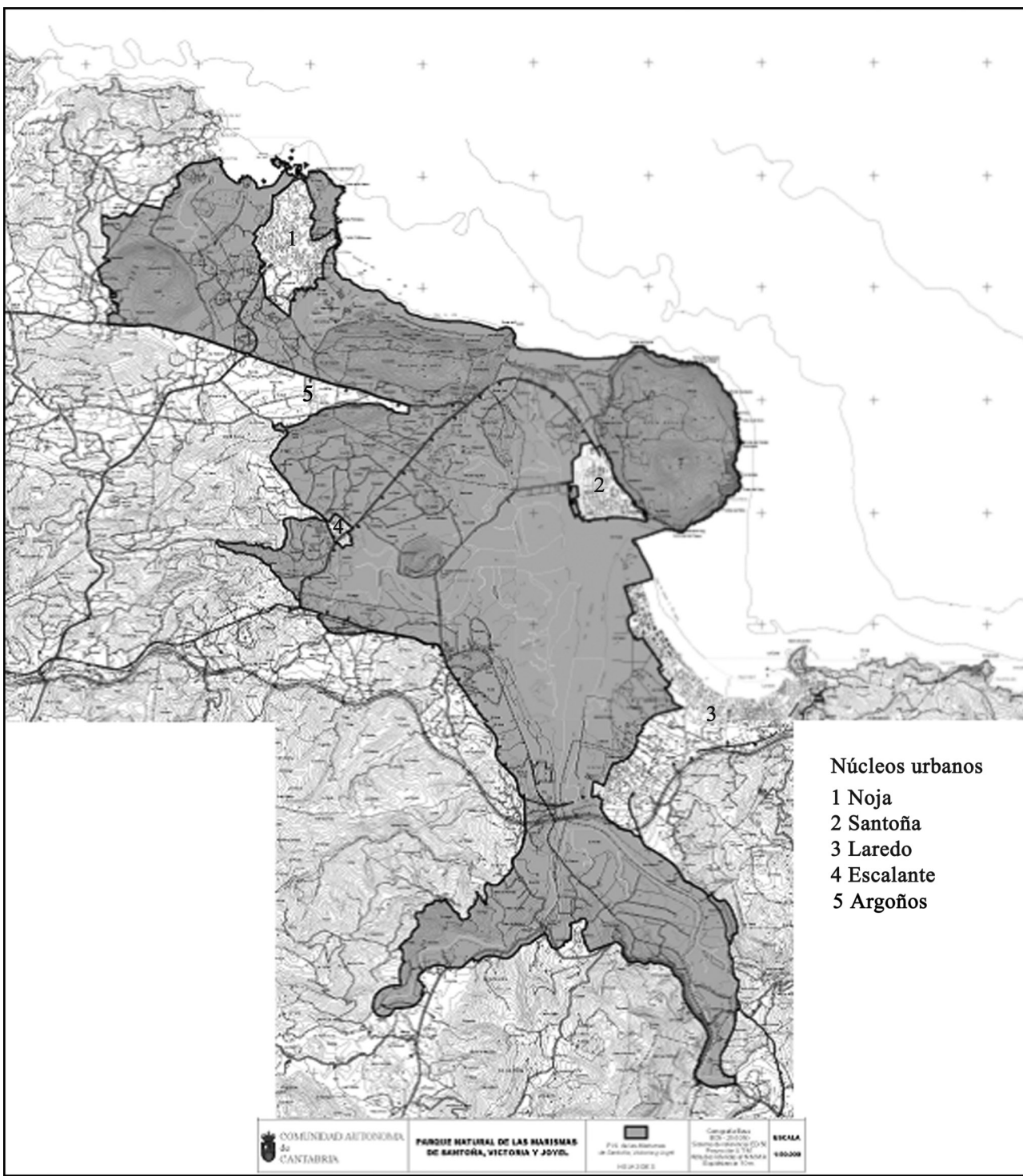

Fuente: reelaboración a partir de cartografía del Gobierno de Cantabria, Consejería de Desarrollo Rural, Ganadería, Pesca y Biodiversidad. 
pio de Argoños, pero la alteración de la zonificación contemplada en el PORN vigente sería el punto de partida para ello.

Las expectativas han sido respaldadas, hasta cierto punto, por las afirmaciones realizadas por el Director del Parque señalando que «la revisión del PORN de las Marismas de Santoña, Victoria y Joyel es una de las medidas que venía contemplada en el Plan de Actuación del Gobierno de Cantabria para las viviendas con sentencia de derribo, a efectos de permitir la legalización de parte de las edificaciones» ${ }^{42}$.

Asimismo es víctima del acoso urbanístico el Parque Natural de las Dunas de Liencres, que todavía carece de PORN aunque sí dispone de PRUG. En febrero de 2002 se inició una campaña en defensa del Parque Natural para tratar de frenar la destrucción de la ladera norte del monte de La Picota, que forma una unidad paisajística y ecológica con el Parque. En esos momentos los planes para La Picota incluían la urbanización de una superficie de 200.000 $\mathrm{m}^{2}$ y la construcción de 196 viviendas unifamiliares. El Ayuntamiento de Piélagos denegó los proyectos previos a la urbanización de los terrenos amparándose en los «informes negativos» que emitió el Gobierno de Cantabria a través de las Consejerías de Ganadería y Obras Públicas. La negativa dio lugar a que la Junta de Compensación, formada por los propietarios de los terrenos de La Picota, acudiera a los tribunales esgrimiendo el Plan General de Ordenación Urbana del año 1986, vigente cuando adquirieron los terrenos, en el que el suelo se registraba como Urbanizable No Programado. Por otra parte la revisión del PGOU hecha en 1993 daba el visto bueno a la actuación urbanística y se había aprobado un Plan Parcial, por lo que el área tampoco se veía afectada por el POL ${ }^{43}$. El proceso ha quedado paralizado a raíz del inicio, en 2006, del proyecto de elaboración de un PORN, aún no presentado.

Uno de los casos más complejos, más expresivos de la conflictividad vinculada a los retrasos y deficiencias del planeamiento ambiental y urbanístico en Cantabria y que mayor impacto mediático ha tenido en los últimos tiempos, ha sido el de la construcción en el municipio de Piélagos de la urbanización «Costa Verde» ubicada en el Alto del Cuco, en la ladera

42 El Diario Montañés, 28/05/2010. «La inminente revisión del Plan de Ordenación de los Recursos Naturales (PORN) de las Marismas de Santoña, Victoria y Joyel es otro de los trámites que, en determinados supuestos, puede conducir a la regularización de algunas de las urbanizaciones afectadas por la ejecución de sentencias de derribo en la región, especialmente en el término municipal de Argoños.» El Diario Montañés, 04/09/2010. El mismo significado tienen las declaraciones hechas por la Directora General de Biodiversidad en el sentido de que la revisión del PORN de esa zona prevé una modificación de sus límites, «dejando fuera determinados núcleos urbanos», para adecuarlos a los criterios comunes de la Red de Espacios Protegidos de Cantabria, aunque también haya insistido en que el objetivo de fijar nuevos límites no es, de forma específica, evitar la demolición de las viviendas con sentencias firmes de derribo construidas en las proximidades.

43 Los terrenos del monte de La Picota, repartidos entre las localidades de Liencres, Mortera y Boo, todos del municipio de Piélagos, son objeto de varios conflictos que han enfrentado a casi un centenar de propietarios de los terrenos situados en un área declarada Bien de Interés Cultural (BIC), con la categoría de Zona Arqueológica, y a una asociación ecologista, Mortera Verde. En 2003 se incluyó buena parte de La Picota dentro del Plan de Ordenación del Litoral (POL), con la figura del Área de Interés Paisajístico. Un año más tarde, la Consejería de Cultura incoó expediente como Bien de Interés Local (BIL); esta figura quedó anulada por vencimiento del plazo pero la misma Consejería presentó en 2008 otra declaración superior, la de Bien de Interés Cultural. A esto se añadió en 2007 la inclusión de un sector, ubicado en la ladera norte de la Picota, en el Plan de Ordenación de los Recursos Naturales del Parque Natural. El Tribunal Superior de Justicia de Cantabria ha desestimado recientemente el recurso presentado por algunos propietarios y la Asociación de Afectados por la Declaración de Bien de Interés de los Terrenos del Monte Picota contra la decisión adoptada por el Consejo de Gobierno de Cantabria en el año 2008. El Diario Montañés, 16/03/2011. 
meridional del citado monte de La Picota, colindante con el Parque Natural de las Dunas de Liencres (Delgado, 2010).

A esta problemática se añade e incluso, a veces, se superpone, la derivada de la aplicación de la Ley de Costas de 1988, como sucede en el caso de las urbanizaciones de Cerrias en Liencres (Piélagos) y del referido campo de Golf de las Dunas de Oyambre.

Aunque la Ley está vigente desde aquella fecha, no ha sido hasta hace pocos años, a partir de 2004, cuando se ha iniciado realmente el proceso de deslinde del dominio público marítimo-terrestre. Es lo que explica la reciente constitución de plataformas y asociaciones de afectados refundidas en 2009 en la Asociación Cántabra de Afectados por la Ley de Costas, integrada, a su vez, en la Plataforma Nacional y Europea del mismo nombre ${ }^{44}$. La Asociación está promoviendo que las Cortes Generales aprueben «a la mayor brevedad» una proposición no de ley instando al Gobierno estatal a que inicie de manera urgente una reforma de la Ley de Costas.

La conflictividad emergente proviene del retraso con que se ha realizado el proceso de deslinde: a principios de 2009, tras más de veinte años de vigencia de la Ley, se había completado el deslinde del $73 \%$ del litoral cántabro, pero aún quedaba pendiente de hacer en algunos municipios del entorno del área periurbana de Santander (Miengo, El Astillero, Camargo $^{45}$, Villaescusa, Marina de Cudeyo, Medio Cudeyo) y, parcialmente, en Ribamontán al Mar, Laredo, Limpias, Santoña, Noja, Santander o Polanco, donde se verá afectado el polígono industrial de Requejada.

El Gobierno de Cantabria y el Ministerio de Medio Ambiente, Medio Rural y Marino han acordado hace poco tiempo buscar soluciones individualizadas con el objetivo de desafectar la mayor superficie de terreno posible y, en caso de que no sea posible, otorgar una nueva concesión por otros treinta años con la finalidad de garantizar la actividad económica y el empleo $^{46}$.

\section{CONCLUSIONES}

Como balance de lo expuesto hasta aquí, es obligado constatar que la protección de los espacios naturales de Cantabria muestra bastantes carencias y deficiencias. Entre otras, la ausencia generalizada de los imprescindibles instrumentos de ordenación, en particular de PORN, del que sólo disponen en estos momentos el Parque Natural de los Collados del

44 La asociación cántabra se ha vinculado recientemente (febrero de 2011) a la de afectados por la Ley de Montes y la Asociación de Maltratados por la Administración para constituir la llamada Plataforma de Asociaciones a favor de Cantabria (PAC) con la finalidad de reforzar su representatividad ante las instituciones.

45 En el caso del municipio de Camargo (donde resultan afectados los polígonos industriales de Raos, La Verde y Herrera), desde el Ayuntamiento, que ha reclamado la suspensión cautelar de la Ley, la Asociación de Afectados por la Ley de Costas en Cantabria y la Asociación de empresarios de Raos, se afirma que la aplicación del deslinde, realizado en 2011, implicaría la destrucción de 1.200 industrias y 25.000 puestos de trabajo directos. Durante la campaña electoral del otoño de 2011, el Partido Popular, a través de Pío García Escudero, actual Presidente del Senado, se ha comprometido a retomar en el Congreso de los Diputados, tras el 20 de noviembre, la reforma de la Ley de Costas que ya aprobó el Senado a instancias de una proposición de ley elaborada por la senadora Leticia Díaz, actual Consejera de Presidencia del Gobierno de Cantabria. El Proyecto de reforma de la Ley de Costas ha sido aprobado por el Consejo de Ministros del Gobierno de España el día 5 de octubre de 2012.

46 El Diario Montañés, 10 de febrero de 2011. 
Asón desde 2004 y el Parque Natural de Oyambre desde finales de 2010. El Parque Nacional de Picos de Europa lo tiene en suspenso y el Parque Natural de las Marismas pendiente de revisión tras su declaración como tal. Por otra parte, sólo el Parque Natural de las Dunas de Liencres y el Parque Natural Saja-Besaya disponen de PRUG.

Puede afirmarse que las carencias y deficiencias que hasta ahora han caracterizado la ordenación y el planeamiento del medio natural, unidas a las nuevas formas que presentan los procesos de crecimiento residencial y de difusión urbana, están provocando importantes y nocivos efectos de degradación ambiental y paisajística en Cantabria, en particular en las áreas litorales.

Pero, si grave es lo anterior, más peligrosa parece la actual utilización de los escasos instrumentos disponibles de planeamiento territorial y protección del medio natural para adaptarlos a la solución de problemas inmediatos, por graves que sean, a través de modificaciones poco explicitadas y coherentes con los objetivos, principios y criterios con que fueron elaborados hasta prácticamente adulterarlos. Tal es el caso de las recientes modificaciones puntuales del Plan de Ordenación del Litoral, de las propuestas de cambio de los límites de Espacios Naturales Protegidos y de la zonificación de sus PORN, cuya finalidad prístina de protección del territorio y del paisaje se ha reorientado hacia la preservación de urbanizaciones con problemas superpuestos de legalidad. Como, asimismo, parece temeraria la instauración legal de mecanismos de complicidad entre los planeamientos de ordenación ambiental y los urbanísticos para burlar las sentencias judiciales.

\section{BIBLIOGRAFÍA}

ALLENDE LANDA, J. (2000): Medio ambiente, ordenación del territorio y sostenibilidad. Centro de publicaciones de la UPV/EHU, Economía y empresa, Bilbao.

BASSOLS COMA, M. (1981): «El Medio Ambiente y la Ordenación del Territorio» en Documentación Administrativa, $\mathrm{n}^{\circ}$ 190, pp. 407-440.

BASSOLS COMA, M. (1982): «Ordenación del territorio y medio ambiente: aspectos jurídicos» en Administración y Constitución: estudios en homenaje al profesor Mesa Moles, pp. 93-130

DELGADO VIÑAS, C. (2008): «Urbanización sin fronteras». El acoso urbanístico a los espacios naturales protegidos» en Boletín de la Asociación de Geógrafos Españoles, $\mathrm{n}^{\circ}$ 47, pp. 271-310.

DELGADO VIÑAS, C. (2010): «La ordenación territorial en Cantabria: normas, planes, proyectos y realidades» en Cuadernos Geográficos de la Universidad de Granada, $\mathrm{n}^{\circ}$ 47, pp. 453-491.

DUDLEY, N. (Ed.) (2008): Directrices para la aplicación de las categorías de gestión de áreas protegidas. UICN, Gland, Suiza.

ECOLOGISTAS EN ACCIÓN (2010): Banderas Negras 2010. Caos en la costa. Madrid.

ECOLOGISTAS EN ACCIÓN (2007): Infracciones Ley de Costas. Madrid.

EUROPARC-España (2005): Integración de los espacios naturales protegidos en la ordenación del territorio. Oficina Técnica de EUROPARC-España, Fundación Fernando González Bernáldez. Madrid. 
EUROPARC-España (2010): Anuario EUROPARC-España del estado de los espacios naturales protegidos 2009. Oficina Técnica de EUROPARC-España, Fundación Fernando González Bernáldez, Madrid.

FERNÁNDEZ GARCÍA, A. (2010): «Difusión urbana, Ordenación del Territorio y desarrollo sostenible» en Ambienta, ${ }^{\circ}$ 88, pp. 20-27.

FROCHOSO, M., GONZÁLEZ, R. y LUCIO, A. (2002): Espacios Naturales de Cantabria. Ed. Creática, Santander.

GÓMEZ PIÑEIRO, J. (1995): «Análisis geográfico, ordenación del territorio y medio ambiente» en Lurralde: Investigación y Espacio, $\mathrm{n}^{\circ}$ 18, pp. 7-20.

ICANE (2010): Anuario Estadístico. Cantabria 2010. Instituto Cántabro de Estadística, Santander.

LUCIO CALERO, A. (2006): «Espacios naturales protegidos y desarrollo rural en Cantabria» en DELGADO VIÑAS, C. (ed.): La Montaña Cantábrica. Una montaña viva. Parlamento de Cantabria y Universidad de Cantabria, Santander, pp. 189-196.

MINISTERIO DE VIVIENDA (2010): Libro Blanco de la Sostenibilidad en el Planeamiento Urbanístico Español. Madrid, Ministerio de Vivienda.

MULERO MENDIGORRI, A. (2002): La protección de espacios naturales en España. Antecedentes, contrastes territoriales, conflictos, perspectivas. Mundi-Prensa, Madrid.

NAREDO, J. M. y F. PARRA (eds.) (2002). Situación diferencial de los recursos naturales españoles. Col. Economía-vs-Naturaleza, Fundación César Manrique, Lanzarote.

OBSERVATORIO DE LA SOSTENIBILIDAD EN ESPAÑA (2006): Cambios de ocupación del suelo en España. Implicaciones para la sostenibilidad. OSE, Ministerio de Medio Ambiente, Madrid.

OBSERVATORIO DE LA SOSTENIBILIDAD EN ESPAÑA (2010): Informe anual de Sostenibilidad en España. OSE, Ministerio de Medio Ambiente, Medio Rural y Marino, Madrid.

PAREJO ALFONSO, L. (1996): «Ordenación del Territorio y Medio Ambiente» en Revista de Derecho Urbanístico y Medio Ambiente, $\mathrm{n}^{\circ}$ 146, pp. 131-178.

PLAZA, J. I., HORTELANO, L. A., DELGADO, C. y GIL, C. (2007): «Espacios naturales protegidos en el sector central y oriental de la Montaña Cantábrica: tipología, problemas, contrastes y valoración de formas de intervención» en Les espaces naturels proteges. IIIe Colloque Franco-Espagnol de Géographie Rurale. AGE y Universidad Internacional de Andalucía, Baeza, pp. 165-188.

PRADOS, M. J. (2009): Naturbanization. New identities and processes for rural-natural areas. Taylor \& Francis Group, Londres.

TROITIÑO VINUESA, M.A. et alii (2005): «Los espacios protegidos en España: significación e incidencia socioterritorial» en Boletín de la Asociación de Geógrafos Españoles, $\mathrm{n}^{\mathrm{o}} 39$, pp. 227-265.

VOTH, A. (2007): «Cambios en las políticas de Espacios Naturales Protegidos y desarrollo sostenible» en La Geografía en la frontera de los conocimientos. Universidad Pablo de Olavide/AGE, Sevilla (CD-rom). 